\title{
A EXCLUSÃO INTELECTUAL DO PENSAMENTO NEGRO ${ }^{1}$
}

\author{
Aline Matos da Rocha ${ }^{2}$
}

\section{RESUMO}

A filosofia em sua dimensão reflexiva, necessita refletir acerca de seu ensino, e reprodução do mesmo, tendo em vista o contexto da implementação do artigo 26-A da Lei de Diretrizes e Bases da Educação Nacional, que determina o estudo das histórias e culturas africanas e afrobrasileiras nos currículos de toda a educação básica, no entanto, encontra um entrave bastante significativo no que diz respeito ao ensino de filosofia: Há um profundo silenciamento e exclusão do pensamento produzido no continente africano. Para cumprir o determinado por esta lei, é necessário descortinar os mecanismos responsáveis por este silenciamento e exclusão, para então, criar um espaço para que este pensamento, que compõe a cultura africana e impacta o pensamento nacional possa ser incorporado aos currículos de Ensino Médio, onde o ensino de filosofia se dá na Educação Básica. Nesse sentido, a escrita desse artigo se propõe a pensar a constituição da exclusão intelectual do pensamento negro-africano (sobretudo o pensamento produzido na porção Subsaariana do continente africano).

Palavras-chave: Filosofia; Exclusão; Pensamento; Negro-Africano; Currículo; Ensino de Filosofia.

\section{RESUMEN}

La filosofía tiene que reflexionar sobre su enseñanza y la reproducción, en la vista del artículo 26-A da Ley de Directrices y Bases de la Educación Nacional, que aboga por el estudio de la historia y las culturas de África y afro-brasileñas en los planes de estudio de toda la educación básica, sin embargo, es un obstáculo muy significativo en lo que respecta a la enseñanza de la filosofía: hay un profundo silenciamiento y exclusión del pensamiento producen en África. La redacíon de este artículo tiene la intencíon de pensar la constitución de la exclusión de los intelectuales pensó negro africano (sobretudo pensando em África Subsahariana).

Palabras claves: Filosofía; Exclusión, Pensamiento, Negro africano, Currículo, Enseñanza de la filosofía.

\footnotetext{
${ }^{1} \mathrm{O}$ presente artigo é resultado do Programa de Iniciação Científica da Universidade de Brasília ProIC/DPP/UnB - PIBIC nas Ações Afirmativas (CNPq) 2012/2013 sob orientação do Prof. Dr. wanderson flor do nascimento.

${ }^{2}$ Graduanda em Filosofia na Universidade de Brasília - UnB. Bolsista do Programa Afroatitude - UnB.
} 


\section{Introdução}

É preciso que a filosofia pense outras perspectivas. Sobre outras perspectivas pensarei a filosofia no contexto da introdução do artigo 26-A da Lei de Diretrizes e Bases da Educação Nacional, que determina a obrigatoriedade do ensino de histórias e culturas africanas e afrobrasileiras em todos os currículos da Educação Básica. Contudo, no ensino de filosofia, há um profundo silenciamento e exclusão intelectual do pensamento produzido no continente africano.

Atenta ao que Cabrera denomina como a exclusão intelectual, quando afirma que,

A "exclusão intelectual" e especificamente filosófica, [são] os processos através dos quais trabalhos filosóficos são ignorados em sua própria existência, no sentido de "passar a não existir", ou mais radicalmente, não conseguem ao menos "chegar a existir" (...). A exclusão que eu quero estudar aqui faz, literalmente, "desaparecer" filosofias; é pois, um conceito mais radical que, por exemplo, "silenciamento", que supõe algo que é silenciado (CABRERA, 2013, tradução minha $\left.{ }^{3}\right)$.

Oponho-me à denominação de Cabrera, pois, considero que a exclusão intelectual do pensamento negro-africano está alicerçada em um profundo silenciamento, desse modo, utilizarei a designação do filósofo sul-africano Ramose, na qual a exclusão intelectual é,

Experimentada como a exclusão dos outros, que não aparecem como sendo o mesmo que nós, ou que são percebidos como uma ameaça à mesmidade inscrita em nossa particularidade. Esta lógica da exclusão foi experimentada historicamente, como o foi para nós, na cristianização e colonização dos outros povos do mundo. O significado filosófico desses eventos históricos é a afirmação de que uma perspectiva particularista pode reivindicar o direito de se impor como a primeira e única experiência, conhecimento e verdade se

\footnotetext{
${ }^{3}$ Utilizo tradução minha em oposição à tradução livre, por reconhecer que toda tradução não é neutra, e expressa uma compreensão particular de quem a faz.
} 
encaixam e tornam válidos para os outros seres humanos independente de suas condições existenciais (RAMOSE, 2011, p. 11).

Nesse sentido, a escrita do presente texto nasce do reconhecimento da necessidade de compreensão dos mecanismos histórico-político-epistêmico-culturais responsáveis pelo silenciamento e exclusão intelectual do pensamento negro-africano (especialmente o pensamento produzido na porção Subsaariana do continente africano). Assim, lanço um olhar na compreensão da dinâmica colonial, não desprezando a filosofia ocidental, porém, pretendendo enxergar (pensar) outras perspectivas.

\section{Concebendo um início de reflexões (ações)}

A filosofia habita sobre um solo reflexivo, que nos coloca em um constante estado de inquietude diante do que nos é apresentado, propiciando um confronto conosco mesmo/a e o Outro, na tentativa de realização plena do humano. Sob essa perspectiva, a filosofia não pode se furtar de colocar a si mesma no centro de suas reflexões, confrontando sua produção de conhecimento, seu currículo e ensino. Constitui um estímulo o estabelecimento da obrigatoriedade da (re) inserção da filosofia no currículo da Educação Básica e a consequente formulação pelo Ministério da Educação das Orientações Curriculares para o Ensino Médio (OCNEM), para refletirmos e problematizarmos sua produção de conhecimento, seu currículo e ensino, tanto nos cursos de graduação quanto na Educação Básica (Ensino Médio), onde o ensino se dá e local em que as/os futuras/os licenciadas/os atuarão.

O documento formulado pelo Ministério da Educação reconhece na filosofia a sua estrita ligação com a formação humana e cidadã, dois princípios que "norteiam" a educação. Entretanto, quando o documento instituído pelo governo ressalta a vinculação da filosofia à formação humana e cidadã, colocamos em evidência esses dois conceitos refletindo o conteúdo ideológico ${ }^{4}$ transmitido. Se a filosofia é uma tentativa de realização plena do humano, as OCNEM sob o discurso da formação humana e cidadã, podem estar sendo

\footnotetext{
${ }^{4}$ Utilizo o conceito de ideologia com base na enunciação do filósofo ganense Kwame Appiah, no qual "as ideologias obtêm êxito na medida em que são invisíveis, no momento em que sua trama de pressupostos fica aquém da consciência" (APPIAH, 1997, p. 94).
} 


\section{A Exclusão intelectual do pensamento negro}

utilizadas como um poderoso instrumento na fabricação de determinados seres humanos, visões de mundo, modos de pensar e lidar com o saber.

As OCNEM, ao ressaltar constantemente uma epistemologia ${ }^{5}$ que respeite a diversidade, propõem um conjunto de diretrizes que estruturam o currículo e o ensino da filosofia a serem ministrados por professoras/es, encobrindo a "diversidade" que é preconizada no próprio currículo, ao normatizar o fazer filosófico, prescrevendo conhecimentos canônicos (institucionalizados), através dos quais ela têm de ser ensinada para as/os estudantes. Essas prescrições são condições adequadamente estabelecidas para a presença da filosofia como disciplina, porém, subalterniza outras formas de conhecimento. Sendo assim, "a filosofia tornou-se um instrumento para a subalternização de formas de conhecimento fora de suas fronteiras disciplinadas" (MIGNOLO, 2003, p. 32).

Há nas Orientações a afirmação de "que não existe uma filosofia [singular], mas filosofias [plural], e que a liberdade de opção dentro de seu universo não restringe seu papel formador" (BRASIL, 2006, p. 21). A sutileza da argumentação está em não levar a pluralidade $^{7}$ a sério e acobertar que a liberdade ${ }^{8}$ de escolha - extremamente condicionada - se concentra dentro de um universo - eurocêntrico, branco - que opta por algo determinado nos moldes euro-norteamericanos. Desse modo, naturaliza as práticas excludentes, que não conseguem perceber que mesmo quando se escolhe "outras filosofias", escolhe a si mesma redução ao cânone - privilegiando determinados modelos de compreensão e significado da filosofia. Para o filósofo sul-africano Ramose, "a compreensão e o significado da filosofia têm como base e refletem a perspectiva daqueles que exercem poder sobre os outros, especialmente poder físico, psicológico e intelectual" (RAMOSE, 2011, p. 09). Essa perspectiva inviabiliza no espaço filosófico a contemplação de uma pluralidade e multiplicidade de pensamentos. Inversamente, a filosofia têm que contemplá-los, assim como “o currículo que se apresenta como a expressão daquilo que constitui o conhecimento e que

\footnotetext{
5 “Coube a epistemologia o domínio do conhecimento e da verdade" (MIGNOLO, 2003, p. 31).

${ }^{6}$ É questionável a formação de um pensamento crítico em filosofia baseada apenas em autores euronorteamericanos.

${ }^{7}$ Sobre o signo da pluralidade a filosofia é transmitida dando ênfase apenas aos conteúdos euro-norteamericanos (eurocêntricos).

${ }^{8}$ Nas Orientações Curriculares para o Ensino Médio a noção de liberdade é compatível com a dominação eurocêntrica.
} 
formam pessoas e mundos" (MACHADO, 2012, p. 24; FLOR DO NASCIMENTO, 2004, p. $37)$.

Ante o exposto, é significativo a mudança na Lei de Diretrizes e Bases da Educação Nacional (LDB) a introdução do artigo 26-A, que ao determinar a obrigatoriedade do estudo das Histórias e Culturas Africanas e Afro-Brasileiras, ressaltando a valorização geopolítica africana e diaspórica, rompe o silêncio imposto pelas ideias eurocêntricas, e abre caminho para a discussão do ensino de filosofia e sua função educativa no que tange ao artigo. Este, ao ter focado especialmente as áreas de história, educação artística e literatura ${ }^{9}$, não citando especificamente a área de filosofia, funciona como rota de fuga para que o saber filosófico atue se eximindo e ignorando o proposto pela presente legislação. Contudo, é preciso que o seu ensino tanto na graduação quanto na Educação Básica se situem na lei. Não obstante, a introdução se depara com dificuldades no que diz respeito a sua adoção. Segundo Flor do Nascimento,

A obrigatoriedade da presença da filosofia como disciplina nos currículos de Ensino Médio aqueceu a já complicada dificuldade de definição dos conteúdos mínimos para a licenciatura em Filosofia, sobretudo quando pensamos que os currículos da graduação e do Ensino Médio têm objetivos, conteúdos e sentidos bem diferentes. Esta dificuldade se acirra em função da determinação do artigo 26-A da LDB por exigir que o Ensino Médio lide com algo que as licenciaturas não têm conseguido trabalhar e que toda a discussão hegemônica acerca do ensino de filosofia ignora: o pensamento africano e afro-brasileiro. Há um drástico silêncio na academia brasileira acerca do que se produziu e se produz filosoficamente no continente africano e nas projeções dessa produção em solo nacional (FLOR DO NASCIMENTO, 2012, p. 75).

Esse drástico silêncio está alicerçado no tratamento que o continente africano comumente recebeu da filosofia europeia, que atribui à África e sua população o caráter de não possuir história, ser selvagem, desumanizada, irracional e bárbara. Citamos $\mathrm{Hegel}^{10}$, a título de "ilustração" desse caráter que ela recebeu da Europa em defesa de sua elevação

\footnotetext{
9 § $2^{\mathrm{o}}$ Os conteúdos referentes à História e Cultura Afro-Brasileira serão ministrados no âmbito de todo o currículo escolar, em especial nas áreas de Educação Artística e de Literatura e História Brasileiras (2007, p. $103)$.

${ }^{10}$ Não podemos negligenciar a tessitura argumentativa que Hegel em sua obra Filosofia da História traça acerca do continente Africano. Porém, não é uma exclusividade da filosofia Hegeliana a inferiorização da população negra, estando presente nos textos de muitos filósofos ocidentais (Kant, Voltaire, Hume, Locke, Rousseau, só para citar alguns).
} 
como centro e portadora do saber universal. "Universal" que desconsidera e rejeita - não enxerga - a diversidade humana atribuindo-lhe não existência.

O caráter tipicamente africano é, por isso, de difícil compreensão, pois para apreendê-lo temos que renunciar ao princípio que acompanha todas as nossas idéias, ou seja, a categoria da universalidade. A principal característica dos [as] negros [negras] é que sua consciência ainda não atingiu a intuição de qualquer objetividade fixa, como Deus, como leis, pelas quais o homem se encontraria com a vontade, e onde ele teria uma idéia geral de sua essência. Em sua unidade indiscriminada e compacta, o africano ainda não chegou a essa distinção de si como indivíduo e de sua generalidade essencial. Por isso, carece também do conhecimento de uma essência absoluta, que seria um outro, superior a ele mesmo. O negro representa, como já foi dito, o homem natural, selvagem e indomável. Devemos nos livrar de toda reverência, de toda moralidade e de tudo o que chamamos sentimento, para realmente compreendê-los. Neles, nada evoca a idéia do caráter humano (HEGEL, 2008, p. 83 -84).

A partir da referência a Hegel, temos que constantemente nos questionar sobre esse conceito - humano. O que a percepção do que ele seja agrega e desagrega? em que contexto foi retirado dos povos africanos? Qual ideia de humano a filosofia europeia evoca? Efetivamente, não é a dos povos negro-africanos, não estando os europeus dispostos a reconhecer nenhuma humanidade negro-africana, no sentido, de que o seu reconhecimento incluiria o da capacidade de pensar, consequentemente, contrariando o raciocínio alicerçado na desumanização dessas pessoas. "Uma vez que os africanos não são propriamente humanos, como firmava o raciocínio, havia uma medida própria e condizente com o tratamento subumano empreendido em relação a eles" (RAMOSE, 2011, p. 08). Essa medida própria e condizente se expressou na colonização, escravização, animalização, destruição dos conhecimentos, resultando no apagamento do mundo negro. Como nos demonstra Césaire, "o mundo negro desacreditado; vozes imensas apagadas para sempre; lugares atirados ao vento (...), a humanidade reduzida a um monólogo" (CÉSAIRE, 2010, p. 79).

Negando o raciocínio da desumanização, reconheceremos a humanidade africana ${ }^{11}$. "Isto desafia a exclusão de longa data da África ou, mais precisamente, sua inclusão como o 'outro' negativo da razão do mundo ocidental nas primeiras tradições da filosofia ocidental moderna" (RAMOSE, 2011, p.16 -17). Dessa forma, pretendemos romper com o tratamento

\footnotetext{
${ }^{11}$ A constante reivindicação pelo reconhecimento da humanidade (humanidade desumanizada) dos africanos é essencial para que os conteúdos e discussões que coloca o pensamento negro-africano sejam por nós acessados. Como exemplo, ver artigo do filósofo sul-africano Mogobe Ramose (2011), que trata "sobre a legitimidade e o estudo da Filosofia Africana".
} 
subumano, que construiu e constrói sistematicamente um pensamento unilateral às expensas do silenciamento e exclusão do pensamento negro-africano. Por conseguinte, entenderemos como a lógica colonial se manifestou e se manifesta na episteme moderna, de modo que os conhecimentos produzidos no continente africano nos sejam completamente negados e desconhecidos, fazendo parte de uma prática hegemônica ${ }^{12}$ da filosofia. De acordo com Flor do Nascimento e Botelho (2010, p. 70), “é impossível entender os efeitos, os sentidos, as dinâmicas e as práticas de poder da Modernidade sem entender que ela tem em sua base uma lógica colonial".

A lógica colonial da modernidade não apenas está ligada ao contexto da colonialidade política, que é este modo de exercício do poder que se funda na base de uma diferença colonial, que hierarquiza experiências, saberes, culturas, vidas, mas também vai sustentar um regime de produção de saberes que o legitima e o faz funcionar, ao mesmo tempo em que estes saberes estão ligados a uma certa imagem de vida, de comunidade, de ensino, de aprendizagem, também colonizadas (FLOR DO NASCIMENTO; BOTELHO, 2010, p. 77).

Visto que a lógica colonial é um dispositivo que afeta profundamente a inclusão e visualização do pensamento negro-africano na filosofia, é necessário descortiná-la, para que este pensamento possa ser acessado, e incorporado aos currículos e ao ensino, de modo não exotizado. Ou seja, a incorporação não pode ser uma "vontade de objetivar, de encaixar, de aprisionar, de enquistar. Frases como: 'eu conheço-os, eles são assim', traduzem essa objetivação levada ao máximo. Assim, conheço os gestos, os pensamentos, que definem estes homens [humanos]. O exotismo é uma das formas desta simplificação" (FANON, 1980, p. 39).

A escritora nigeriana Chimamanda Adichie $^{13}$ (2009), também nos chama atenção para a incorporação do pensamento negro-africano nos moldes do estereótipo. Para ela, "o problema com estereótipos não é que eles sejam mentira, mas que eles sejam incompletos".

Diante disso, como pensamos o que está distante de nós, (ideologicamente colocado distante - África)? principalmente o pensamento negro-africano, que nos foi - quando o foi apresentado como não existente, estranho, irracional. Não podemos escamotear que nossa

\footnotetext{
${ }^{12}$ A hegemonia é um projeto político de manutenção de padrões.

${ }^{13}$ Veja o vídeo no youtube "O perigo da história única" da contadora de história, e escritora nigeriana Chimamanda Ngozie Adichie. (www.youtube.com/watch?v=ZUtLR1ZWtEY).
} 
educação em África foi - é - uma educação veiculada por estereótipos motivados por um ensino colonial. Segundo o filósofo ganense Appiah, “o ensino colonial, em suma, produziu uma geração imersa na literatura dos colonizadores, uma literatura que amiúde refletia e transmitia a visão imperialista" (APPIAH, 1997, p. 87).

Essa visão imperialista ${ }^{14}$ inscreveu em nossa subjetividade: histórias, imagens, maneiras assimétricas de nos relacionar com o continente africano, que só são possíveis de ser (des) construídas, e visualizadas de outra forma, com a descolonização do nosso próprio pensamento. Ou seja, não podemos incorporar aos currículos e ao ensino de filosofia o pensamento negro-africano alicerçados na lógica colonial, remoldando a geopolítica racista sem realmente confrontá-la. Portanto, "sua promoção não poderá certamente fazer-se num quadro neocolonial” (SOW, 1977, p. 26), implicando na produção de um conhecimento exotizado e estereotipado, que contribuem na reprodução e perpetuação de incompletudes.

\section{O racismo e a diferença colonial}

Parte da explicação deve residir (...), no racialismo: que reação seria mais natural, ante uma cultura europeia, que afirma com (...) Hegel que o intelecto é propriedade dos homens de pele branca, do que insistir em que há algo importante na esfera do intelecto pertencente às pessoas negras?

Kwame Appiah (1997, p. 136)

Um dos eixos centrais para a compreensão da exclusão intelectual do pensamento negro está concentrado no racismo ${ }^{15}$. De acordo com a conceituação da poetisa e pensadora negra Audre Lorde, o "racismo é a crença na superioridade inerente de uma raça sobre a outra e, assim, em seu direito de dominar” (LORDE, 1984, p. 07, tradução minha). Nesse sentido, não podemos ocultar que os/as pensadores/as africanos/as que estão produzindo pensamento são pessoas negras, que historicamente foram marcadas com um signo ${ }^{16}$, que os/as inferiorizou em nome da superioridade de determinada raça (branca) sobre outra (negra). Dessa maneira, "não é possível subjugar homens [humanos], sem logicamente os inferiorizar

\footnotetext{
${ }^{14}$ Universalização de um padrão que desumaniza a cultura, o conhecimento do Outro.

${ }^{15} \mathrm{O}$ racismo está na base da inferiorização e subalternização do pensamento africano.

${ }^{16}$ Ser negro [negra] significa exibir os traços que lembram e remetem à derrota histórica dos povos africanos perante os exércitos coloniais e sua posterior escravização. De modo que alguém pode ser negro [negra] e não fazer diretamente parte dessa história - isto é, não ser descendente de ancestrais apreendidos e escravizados -, mas o significante negro que exibe será sumariamente lido no contexto dessa história (SEGATO, 2005, p. 04).
} 
de um lado a outro. E o racismo não é mais do que a explicação emocional, afetiva, algumas vezes intelectual, desta inferiorização" (FANON, 1980, p. 44).

Consequentemente, a inferiorização da raça negra promovida pela lógica colonial, justificou a "exploração, torturas, razias, racismo, liquidações coletivas, opressão racional, (...) para fazerem literalmente, do autóctone um objeto nas mãos da nação ocupante. Este homem [humano] objeto, sem meios de existir, sem razão de ser, é destruído no mais profundo da sua existência" (FANON, 1980, p. 39).

Essa destruição trouxe em seu âmago uma destruição cognitiva. Pois, quem domina materialmente, domina também intelectualmente, resultando no que Abdias do Nascimento conceituou de mentecídio, chamando atenção para o caso dos afro-brasileiros,

Entre os mecanismos executores do linchamento social do afro-brasileiro deixando de lado a miscigenação compulsória, que significa o embranquecimento forçado do negro [negra] como único meio da melhoria sócio-econômica; indo além do preconceito de cor, da discriminação e da segregação raciais, os supremacistas brancos e brancóides manejam simultaneamente outras ferramentas de controle social do povo negro, exercendo sobre ele constante lavagem cerebral, visando entorpecer ou castrar sua capacidade de raciocínio. Esta tarefa vil quase não encontra obstáculos à sua frente, devido à situação de permanente penúria, fome, degradação física e moral, em que são mantidos as massas afro-brasileiras. Esta forma de mentecídio contribui muito significativamente para o resultado ótimo buscado pela estratégia do seu aniquilamento total (NASCIMENTO, 1980, p. 25).

A estratégia do aniquilamento movida pela dominação do racismo desestrutura o panorama social do continente africano, destruindo e esmagando seus sistemas de referências. Dessa forma, sua população é constantemente esvaziada de pensamento.

Com efeito, o profundo silenciamento e subalternização do pensamento negroafricano, são reflexos da exclusão justificada pela superioridade dos europeus sobre a raça negra, estabelecendo incessantes relações de dominação colonial. Atrelado a isso, está o que Mignolo conceituou como diferença colonial, - que traz como $\mathrm{um}^{17}$ de seus fundamentos a raça $^{18}$ - como um espaço de hierarquização e de valoração de conhecimentos e de sua

\footnotetext{
${ }^{17}$ Existe outros fundamentos como a inteligência, as línguas, religião. Porém, podemos notar que essas outras categorias podem ser agrupadas na raça. É como se fossem seus correlatos.

${ }^{18}$ A raça atua como uma hierarquia proeminente.
} 
produção, tendo em vista a classificação de um povo como superior ou inferior. Segundo Mignolo,

A diferença colonial é o espaço onde emerge a colonialidade do poder. A diferença colonial é o espaço onde as histórias locais que estão inventando e implementando projetos globais encontram aquelas histórias locais que os recebem; é o espaço onde os projetos globais são forçados a adaptar-se, integrar-se ou onde são adotados, rejeitados ou ignorados. A diferença colonial é, finalmente, o local ao mesmo tempo físico e imaginário onde atua a colonialidade do poder, no confronto de duas espécies de histórias locais visíveis em diferentes espaços e tempos (MIGNOLO, 2003, p. 10).

Seguida da conceituação de Mignolo, é necessário definir o que significa colonialidade do poder, termo cunhado pelo sociólogo peruano Aníbal Quijano, para compreendermos a diferença colonial. Em Quijano,

Foi estabelecida uma relação de dominação direta, política, social e cultural dos europeus sobre os conquistados de todos os continentes. Essa dominação é conhecida como colonialismo. (...) Contudo, a colonialidade, em consequência, é ainda o modo mais geral de dominação no mundo atual, uma vez que o colonialismo, como ordem político explicito, foi destruído. Ela não esgota obviamente, as condições nem as formas de exploração e dominação existentes entre as pessoas. Mas não parou de ser, há 500 anos, seu marco principal. As relações coloniais de períodos anteriores provavelmente não produziram as mesmas sequelas e, sobretudo, não foram a pedra angular de nenhum poder global (QUIJANO, 1992, p. 01 - 04).

Dessa forma, "o entendimento da colonialidade do poder pressupõe a diferença colonial como sua condição de possibilidade, e como aquilo que legitima a subalternização do conhecimento, e a subjugação dos povos" (MIGNOLO, 2003, p. 40). Portanto, a diferença colonial atuando na legitimação ${ }^{19}$ e subalternização dos conhecimentos, sub-intelectualiza uma população, impondo o seu pensamento (hegemônico) constituído como superior, justificando as inferioridades, e estabelecendo relações entre colonizador e colonizado e, assim, em seu direito de dominar assentado na ideia de que o seu conhecimento se constitui como uma forma adequada dos povos subjugados conhecerem, e se enquadrarem.

Fundamentado nessa ideia, o colonizador crê que o seu conhecimento é bom. Assim, a sua implementação sempre será boa para quem a enuncia, porém, invisibiliza as relações que há entre conhecimento e controle social, é por isso, que o pensamento negro-africano segue sendo excluído, pois, a diferença colonial sendo o espaço onde emerge a colonialidade do

${ }^{19}$ Essa sendo um jogo de poder extremamente eficaz. 
poder, constantemente constrói, e transforma diferenças em valores, resultando na marginalização, subalternização e negação desse pensamento. No sentido que na hierarquização do que seja intelectualmente aceito como um conhecimento superior, ele consta como algo a ser desprezado. Desta maneira, há uma inferiorização do pensamento negro-africano promovido pelo racismo em consonância com a diferença colonial. Destarte, a produção filosófica hegemônica está atravessada pela relação entre racismo e diferença colonial, que distinguem o que é conhecimento e o que não é conhecimento (humano e não humano), esse vínculo impregna todos os elementos da vida social (as instituições, os currículos das escolas e dos cursos universitários, o senso comum, o imaginário, etc).

\section{(Re) significar a história}

Não é possível libertar-se de situações de opressão se você não sabe qual é sua história, se não entende por que está nisso, se não reconhece como os opressores são mais fortes do que você porque têm não apenas mais armas, mas mais crueldade também. (Alice Walker)

É salutar, portanto, para o ensino da Filosofia que nunca se desconsidere a sua história, em cujos textos reconhecemos boa parte de nossas medidas de competência e também elementos que despertam nossa vocação para o trabalho filosófico. Mais que isso, é recomendável que a história da Filosofia e o texto filosófico tenham um papel central no ensino da Filosofia (BRASIL, 2006, p. 27).

As Orientações Curriculares para o Ensino Médio enfatizam a relevância da "História da Filosofia" em seu ensino, porém, essa "História" tem de ser (re) vista e contada de outro jeito. Possuímos uma história da filosofia adepta da versão colonial. Um exemplo emblemático disso está a Filosofia da História de Hegel, que nega violentamente a África como portadora de história,

África propriamente dita ficou fechada para o resto do mundo; é a terra do ouro, voltada para si mesma, a terra-criança que fica além da luz da história autoconsciente, encoberta pelo negro manto da noite. Sua incomunicabilidade não decorre apenas de sua natureza tropical, mas também - e essencialmente - de sua constituição geográfica. Com isso, deixamos a África. Não vamos abordá-la posteriormente, pois ela não faz parte da história mundial; não tem nenhum movimento ou desenvolvimento para mostrar, e o que porventura tenha acontecido nela -melhor dizendo, no norte dela - pertence ao mundo asiático e 
ao europeu. (...) O Egito será abordado como transição do espírito humano do Oriente para o Ocidente, mas ele não pertence ao espírito africano. Na verdade, o que entendemos por África é algo fechado sem história, que ainda está envolto no espírito natural, e que teve que ser apresentado aqui no limiar da história universal" (HEGEL, 2008, p.82, 83 - 88).

Essa imagem da África (cunhada por Hegel) promoveu de modo rígido uma exclusão de todos os conhecimentos do continente africano. Porém, é preciso que isso seja problematizado $^{20}$. Começando por reconhecer a importância do Egito na formação do pensamento antigo (grego), não como uma transição do espírito humano do Oriente para o Ocidente como evocou Hegel, mas, em contraposição a ele, como pertencente - sim - ao espírito africano. De acordo com o filósofo sul-africano Ramose, "a atenção voltada para a história da filosofia deveria sempre lembrar cuidadosamente da dívida da filosofia grega para com o antigo Egito africano" (RAMOSE, 2011, p. 13). Ou seja:

Desde os tempos mais remotos, desde Homero e Hesíodo, foram os gregos os primeiros europeus que descobriram a África através do Egito. A Grécia, em cuja colônia de Mileto nasce a filosofia ocidental a partir do modelo egípcio, foi um povo culto interessado em achar uma nova visão do cosmos naturalmente diferente da de sua cidade estado. Seus grandes intelectuais, filósofos e historiadores, ao embarcar no norte da África, no Egito, observaram que seus habitantes eram Aithiopes: eram negros e, ante esta evidência, batizaram todo o continente (fundamentalmente o que se estendia ao sul ao longo do rio Nilo) com o nome de Aithiopía o País dos Negros (ONDÓ, 2006, p. 26).

Nesse sentido, um dos grandes filósofos da História Africana, Cheikh Anta Diop, com o seus estudos e pesquisas sobre a origem dos antigos egípcios, refuta Hegel, nos demonstrando que,

a base da população egípcia no período pré-dinástico era negra. Assim, todas elas são incompatíveis com a teoria de que o elemento negro se infiltrou no Egito em período tardio. Pelo contrário, os fatos provam que o elemento negro era preponderante do princípio ao fim da história egípcia, particularmente se observarmos, uma vez mais, que o "mediterrânico" não é sinônimo de "branco". Assim, fica evidente que toda a população egípcia era negra, com exceção de uma infiltração de nômades brancos no período protodinástico (DIOP, 2010, p. 04).

Contudo, fomos educadas/os com a ideia de que "a filosofia não tem geografia". Desse modo, há um profundo distanciamento dos lugares de pensamento e das pessoas que o estão produzindo. É a partir disso que emerge a rejeição de qualquer ligação da África a Europa. Consequentemente,

\footnotetext{
${ }^{20}$ Por que na História da Filosofia essas coisas não são problematizadas, refletidas e discutidas? 
para os românticos e os racistas dos séculos XVIII e XIX resultava simplesmente intolerável que a Grécia, que se considerava não só o resumo da Europa inteira, senão também seu berço, fora produto de uma mescla de europeus nativos e de alguns colonizadores africanos e semitas. Por isso é que se devia descartar o modelo antigo e ser substituído por outro mais aceitável" (BERNAL, 1987, p. 30, tradução minha).

Dessa forma, o modelo mais aceitável de filosofia foi o eurocentrado, que se auto justificou se apossando do racional ${ }^{21}$, mas, não podemos desconsiderar sobre que critérios essa justificação foi consolidada. Notadamente, através de critérios de exclusão, que negam violentamente a África e sua história. Inversamente, como nos demonstra o mestre da tradição oral africana e filósofo tradicionalista Hampaté Bâ, "na África tudo é História" (HAMPATÉ BÂ, 2010, p. 184). Nesse sentido, a importância da história na reivindicação do pensamento negro-africano é essencial. Há uma demanda dos/das pensadores/as negros/as por uma reconstrução histórica da filosofia produzida no continente africano, desde suas próprias bases histórico-culturais, das quais foram despojados.

Outra ideia que é preciso desmistificar na relação da filosofia com sua história, é acerca de seus textos filosóficos, o que nos remete à questão da escrita, em oposição ao continente africano que foi marcado pelo Ocidente como ágrafo. Esse é um estereótipo que precisamos desconstruir, pois, serve como um critério de justificação da exclusão do pensamento negro-africano, e um princípio que toma como referência de filosofia, apenas os “textos". Desse modo, existe a supremacia da escrita, não estando ela aludida ao continente africano. Segundo Mignolo (2001), "você percebe que tudo o que ocorreu no discurso colonial [foi feito] por meio de uma escrita que estava ligada a escrita (alfabética) da história (oficial), e que depois se repetiu em etapas posteriores".

Essa escrita (alfabética) serve para menosprezar a oralidade ${ }^{22}$, sem levar em consideração algo que o mestre tradicionalista Tiener Bokar nos evidencia: "a escrita é uma coisa, e o saber outra. A escrita é a fotografia do saber, mas não o saber em si. O saber é uma luz que existe no homem [humano]. A herança de tudo aquilo que nossos ancestrais vieram a conhecer e que se encontra latente em tudo o que nos transmitiram, assim como o baobá já existe em potencial em semente" (HAMPATÉ BÂ, 2010, p.167).

\footnotetext{
${ }^{21}$ Racional em oposição ao irracional, aludido aos povos africanos.

${ }^{22}$ Base das cosmovisões africana.
} 
Dessa maneira, temos que problematizar a noção de escrita, considerando-a algo a mais do que um mero registro. Pois, "nada prova a priori que a escrita resulta em um relato da realidade mais fidedigna do que o testemunho oral transmitido de geração a geração" (HAMPATÉ BÂ, 2010, p.168).

Nas culturas ocidentais, há um culto à escrita como algo extremamente verdadeiro, no qual o pensamento é depositado. Entretanto, o pensamento negro-africano nos chama atenção para o fato de que o texto escrito nem sempre captura a vitalidade em que se exprime. De acordo com a escritora do Burkina Faso Sobonfu Somé, “existe uma palavra em Dagara que é traduzida como 'a coisa que o conhecimento não pode comer'” (SOMÉ, 2007, p.09). Segundo Somé, o pensamento ${ }^{23}$ aqui é uma experiência existencial vivida, e não é desprovido de oralidade, sendo um constante diálogo com os ancestrais ${ }^{24}$ e seus valores.

Conectadas/os com o que Somé nos apresenta, evocaremos a ancestralidade. De acordo com Oliveira, “a ancestralidade é uma categoria de relação, ligação, inclusão, mistério e revelação-profecia. Indica e esconde caminhos. A ancestralidade é um modo de interpretar e produzir a realidade. Dessa forma, a ancestralidade se converte no princípio máximo da educação" (OLIVEIRA, 2007, p. 257 - 259).

No entanto, esses princípios foram - são - duramente rechaçados pelo pensamento ocidental (eurocêntrico), que nega (intencionalmente) sistematicamente a ancestralidade africana, e o pensamento negro-africano no ensino e currículo de filosofia. Portanto, é necessário que a história da filosofia seja (re) significada, para que essas vozes silenciadas possam falar, e serem ouvidas.

\section{Inconclusa conclusão}

Termino minha escrita com esse título, para que ela possa ser um convite de começo e conclusão com o Outro. Pois, o desafio está posto a todos/as nós: a diferença que deverá ser considerada e pensada. Precisamos pensar a "diferença". Pois, não podemos ocultar que o

\footnotetext{
${ }^{23}$ Ressalto aqui o que Platão chamou de pensamento. Como um diálogo do humano consigo mesmo.

24 "Os ancestrais também são chamados de espíritos. O espírito de um ancestral tem a capacidade de ver não só o mundo invisível do espirito, mas também este mundo. Assim, serve como nossos olhos dos dois lados. É esse poder dos ancestrais que nos ajuda a direcionar nossa vida e evitar os abismos" (SOMÉ, 2007, p. 26). 
pensamento negro-africano tem um fio condutor diferenciado do pensamento europeu. Nesse sentido, temos que trazer outros paradigmas na construção de uma consciência plural na filosofia, que terá que incluir esses conhecimentos, saberes, pensamentos, assim, reescrevendo a sua história, dando visibilidade à História da Filosofia Africana, inserindo e articulando a produção dos/as pensadores/as negros/as, para que dessa forma se cumpra o determinado pelo artigo 26-A.

\section{Referências}

ADICHIE, Chimamanda. Os perigos de uma história única. Disponível em <http://www.youtube.com/watch?v=ZUtLR1ZWtEY>. Acesso em 12 mai 2013.

APPIAH, Kwame. Na casa de meu pai. A África na Filosofia da Cultura. Rio de Janeiro: Contraponto, 1997.

BERNAL, Martin. Atenea Negra: las raices afrosiáticas de la civilizacíon clássica. Teófilo de Lozoya (Trad). Vol. I. Ed. Crítica, 1987.

BRASIL/MEC. Orientações Curriculares Nacionais para o Ensino Médio. Ciências Humanas e suas Tecnologias. Brasília: MEC/SEB, 2006.

CABRERA. Julio. Exclusion intelectual e desaparicion de filosofias (Los condenados del saber). CECIES. Pensamiento Latino Americano y Alternativo. Disponível em: $<$ http://www.cecies.org $>$. Acesso em 24 mai 2013.

CÉSAIRE, Aimé. Discurso sobre o colonialismo. Anísio Garcez Homem (Trad.). Ed. Letras Contemporâneas, 2010.

DIOP, Cheikh, Anta. A origem dos antigos egípcios. In: Gamal Mokhtar (ed.). História Geral da África II. África Antiga. Brasília: Unesco, 2010. 
FANON, Frantz. Em defesa da revolução africana. Isabel Pascoal (Trad.). $1^{\text {a }}$ edição portuguesa, 1980.

FLOR DO NASCIMENTO, Wanderson. Esboço de Crítica à Escola Disciplinar. Ed. São Paulo: Edições Loyola, 2004.

FLOR DO NASCIMENTO, Wanderson. Outras Vozes no Ensino de Filosofia: o pensamento africano e afro-brasileiro. Revista Sul-Americana de Filosofia e Educação. Número 18, maiout/2012, p. 74-89.

FLOR DO NASCIMENTO, Wanderson; BOTELHO, Denise. Colonialidade e Educação. O currículo de filosofia brasileiro entre discursos coloniais. Revista Sul-Americana de Filosofia e Educação. Número 14, mai-out/2010, p. 66-89.

HAMPATÉ BÂ, Amadou. A tradição viva. In: KI-ZERBO, Joseph (Ed.). História Geral da África I. Metodologia e Pré-história da África. Brasília: Unesco, 2010.

HEGEL, Georg Wilhelm Friedrich. Filosofia da História. Maria Rodrigues e Hans Harden (Trad). $2^{\circ}$. Ed. Universidade de Brasília, 2008.

LORDE, Audre. La hermana, la extranjera. LIFS: Lesbianas Independientes Feministas Socialistas, $1984 . \quad$ Disponível em: $<$ http://www.lifsperu.org/files/pdf/cendoc/lecturas\%20lesbicas/Audre\%20LordeLa\%20Hermana\%201a\%20Extranjera.pdf>. Acesso em 21 mar 2013.

MACHADO, Adilbênia Freire. Filosofia africana e currículo: aproximações. Revista SulAmericana de Filosofia e Educação. Número 18, mai-out/2012, p. 4-27.

MARCON, Frank; SOGSBOSSI, Hippolyte Brice. Estudos africanos, história e cultura afrobrasileira: olhares sobre a Lei 10.639/03. São Cristovão: Editora UFS, 2007.

MIGNOLO, Walter. Histórias Locais/Projetos Globais. Colonialidade, Saberes Subalternos e Pensamento Liminar. Belo Horizonte: Ed. UFMG, 2003.

Sobre la diferencia colonial, o acerca de la emergência de um pensamiento que no ha sido considerado como tal. Ciberletras: Revista de crítica literaria y de cultura. Yale/New 
York, n.8, dec. 2002. Disponível em:

$<$ http://www.lehman.cuny.edu/ciberletras/v08/gomez.html $>$. Acesso em 11 jun 2013.

NASCIMENTO, Abdias do. Quilombismo. Vozes: Petrópolis, 1980.

OLIVEIRA, Eduardo. Filosofia da Ancestralidade: corpo de mito na filosofia da educação brasileira. Curitiba: Ed. Gráfica Popular, 2007.

ONDÓ, Eugenio Nkogo. Síntesis sistemática de la filosofía africana. Barcelona: Carena, 2006.

QUIJANO, Aníbal. Colonialidade e Modernidade/Racionalidade. In: Bonillo, Heraclio (comp.). Los conquistados. Bogotá: Tercer Mundo Ediciones; FLACSO, 1992, pp. 437-449. Tradução de wanderson flor do nascimento.

RAMOSE, Mogobe B. Sobre a legitimidade e o estudo da filosofia africana. Ensaios filosóficos, Vol. IV - out/2011, p. 6-23.

SEGATO, Rita. Raça é Signo. Série Antropologia. Brasília, 2005.

SOMÉ, Sobonfu. O espírito da intimidade: ensinamentos ancestrais africanos sobre maneiras de se relacionar. Deborah Weinberg (Trad.). 2 . Ed. São Paulo. Odysseus Editora, 2007.

SOW, Alpha I. Introdução à cultura africana. Emanuel L. Godinho; Geminiano Cascais Franco e Ana Mafalda Leite (Trad.). UNESCO: Edições 70. Lisboa, 1977. 